\title{
DOSSIÊ: DIMENSÕES DE PRIVATIZAÇÃO NA EDUCAÇÃO BÁSICA: DIFERENTES CONTEXTOS EM ANÁLISE
}

\author{
DOSSIER: DIMENSIONES DE PRIVATIZACIÓN EN LA EDUCACIÓN BÁSICA: \\ DIFERENTES CONTEXTOS EN ANÁLISIS
}

\author{
DOSSIER: PRIVATIZATION DIMENSIONS IN BASIC EDUCATION: DIFFERENT \\ CONTEXTS IN ANALYSIS
}

Teise GARCIA ${ }^{1}$

\section{APRESENTAÇÃO}

O Dossiê reúne reflexões desenvolvidas a partir do V Seminário Internacional do Greppe: Dimensões da privatização na Educação Básica, realizado em agosto de $2017 .{ }^{2} \mathrm{O}$ objetivo é contribuir no debate sobre complexidade das dimensões da privatização e suas decorrências para consecução do direito à educação em diferentes contextos.

Assume-se que a privatização na educação implica transferência de bens e responsabilidades para o setor privado, mas também a adoção por parte o setor público de instrumentos próprios à gestão privada (ADRIÃO, 2015, ADRIÃO 2009, GARCIA et al., 2009). A este respeito concorda-se com Licínio Lima (2013) quando este observa que a complexidade nos processos de privatização pode significar a adoção de princípios e prescrições próprias à denominada "Nova Gestão Pública”, instaurando-se na administração pública o que o autor designa como "cânone gerencialista". (LIMA, 2013, p. 179)

O primeiro artigo que compõe o dossiê, "Estado do conhecimento sobre financiamento da educação obrigatória e privatização a partir do Web of Science, 2015-2018”, de autoria de

\footnotetext{
${ }^{1}$ Universidade de São Paulo (USP), Ribeirão Preto - SP - Brasil. Departamento de Educação, Informação e Comunicação. Tem experiência na área de Educação, com ênfase em Administração Educacional e Administração de Unidades Educativas na Educação Básica, desenvolvendo pesquisas sobre a gestão educacional no contexto das relações entre o público e privado. Coordena Seção Grupo de Estudos e Pesquisas em Política Educacional, Greppe-USP/RP. É vice-diretora estadual da Anpae (2017-2019), integra a Fineduca e é associada da Anped. Coordena o Programa de Pós-Graduação em Educação da FFCLRP (2017-2019). ORCID: <https://orcid.org/0000-0003-4351-3159>. E-mail: teiseg2@gmail.com

${ }^{2}$ A realização Seminário foi possível graças ao apoio da Fapesp, CNPq e Capes.
} 
Audrey Mori e Theresa Adrião apresenta instigantes resultados de levantamento em periódicos internacionais sobre os temas financiamento e privatização na educação básica obrigatória. A correlação entre financiamento e privatização fica demonstrada pelos autores, que registram a relevância de se considerar o descritor financiamento em levantamentos relativos à privatização. Os autores também localizam que, dentre os trabalhos que abordam a privatização, a maioria é produzida por autores estadunidenses. O tema mais frequente nos textos localizados é a escolha parental.

O artigo O papel da Parceria Global para a Educação na promoção dos referentes da globalização nos PALOP, de autoria de Rui da Silva, pesquisador do Centro de Estudos Africanos da Universidade do Porto, traz a reflexão sobre as eventuais possibilidades de privatização da educação presentes nos chamados Planos Setoriais de Educação de Cabo Verde, Guiné-Bissau, Moçambique e São Tomé e Príncipe. O autor por meio de análise documental, aproxima-se das proposições para a educação contratualizadas no contexto da Parceria Global para a Educação, iniciativa que inclui governos de países, "agências das Nações Unidas, organizações não-governamentais (ONGs), fundações e empresas (GPE, 2017)". A contribuição do autor, ao analisar um contexto distanciado geograficamente do brasileiro, além de nos propiciar importantes reflexões sobre políticas de caráter global, contribui substancialmente para o firmamento do diálogo necessário entre pesquisadores de ambos os hemisférios.

Na sequência, as pesquisadoras Maria Vieira Silva e Leonice Matilde Richter, em artigo intitulado A adoção da Nova Gestão Pública nas agendas governamentais em diferentes países: influências nas reformas educacionais e no Ensino Médio mineiro, discutem primeiramente a noção de Nova Gestão Pública como perspectiva para diferentes contextos nacionais e, na sequência, a sua adoção como orientação política por parte do governo mineiro. A análise, com farto recurso a fontes primárias e secundárias, elabora cuidadosamente as articulações entre a política local e as demandas de reestruturação do capital, problematizando a redefinição do sentido público da escola pública. As autoras concluem que o interesse da esfera privada no campo educacional, além de se referir a autovalorização dos próprios provedores privados, contribui para "a produção de um novo homo economicus", adequado ao modelo neoliberal que se instala em diferentes contextos.

O quarto trabalho que compõe este dossiê é de autoria pesquisadora Sabrina Moehleck que analisa a evolução do acesso ao ensino integral, na perspectiva de ampliação do direito à educação, tema fundamental em tempos de privatização. $\mathrm{O}$ artigo, Tendências do acesso à educação integral no Brasil: percursos dissonantes na Educação Básica, é organizado a partir 
de pesquisa documental minuciosa por meio da qual a autora conclui que, aparentemente, houve ampliação das oportunidades educacionais, mas registra que novos estudos são necessários a fim de aprofundar as reflexões. A autora destaca, sobretudo as peculiaridades no caso do ensino médio.

Em continuidade ao exame de diferentes contextos e possibilidades de privatização, os quatro textos seguintes examinam a incidência do setor privado no âmbito da organização curricular e da gestão educacional e escolar em contexto diferenciados.

Andresa Costola e Raquel Fontes Borghi, examinam a atuação do "Movimento Todos pela Base Nacional Comum" no artigo Os reformadores Empresariais e as políticas educacionais: análise do Movimento Todos pela Base Nacional Comum. As autoras concentram a reflexão no conteúdo dos discursos presentes nos documentos produzidos pelos atores privados. Mapeiam ainda os sujeitos e instituições presentes neste movimento. As autoras finalmente problematizam os interesses de tais atores na oferta de "soluções" para a educação nacional.

No campo da gestão educacional a introdução das avaliações de larga escala no Estado de São Paulo é analisada no artigo 20 anos de produção científica sobre o SARESP (19962016): reflexões acerca dos desdobramentos na prática docente da privatização, de autoria de Hayla Emanuelle Torrezan, Regiane Bertagna Henrique Kendi Nakamura. A partir de criterioso levantamento de teses e dissertações realizado nos bancos de dados da CAPES e das três universidades públicas paulistas, Unesp, Unicamp e USP, os autores se debruçam sobre as reflexões constantes em tais produções, o que lhes permite mostrar que os trabalhos em análise evidenciam que a privatização se articula à implementação das avalições em larga escala.

O sétimo artigo deste dossiê escrito por Antônio Lisboa Leitão, intitula-se Políticas Governamentais para a Educação Básica na Paraíba: a privatização como estratégia de hegemonia, analisa as políticas governamentais para a Educação no Estado da Paraíba e programas com a presença do setor privado. A partir de dados obtidos pela pesquisa Mapeamento das estratégias de privatização da Educação Básica no Brasil - (2005-2015) (ADRIÃO, 2018), o autor caracteriza um conjunto de programas e entidades privadas que incidem sobre o currículo, a gestão e a oferta educacional na rede estadual paraibana, indicando que se consolida o gerencialismo na administração pública, enraizando-se a perspectiva privatista para o funcionamento da "coisa pública".

O último texto deste Dossiê, de autoria de Teise Garcia, A gestão escolar no contexto da privatização da Educação Básica, problematiza a incidência de atores privados na gestão escolar. Também a partir de dados recolhidos pela pesquisa Mapeamento das estratégias de 
privatização da Educação Básica no Brasil - (2005-2015) (ADRIÃO, 2018; GARCIA, ADRIÃO, 2018), demonstra a difusão de programas que visam a "reformar a gestão da escola", questionando o legado de tais programas para a organização do trabalho na unidade de ensino.

Ao encerrar esta apresentação, espera-se ter-se evidenciado o esforço dos autores em contribuir para a reflexão crítica, com sólidas bases teóricas e empíricas. Em tempos nebulosos, no Brasil pós-golpe, quando se vive a ampla disseminação de fake-news como fontes irrefutáveis na formação da opinião", acredita-se firmemente na socialização do conhecimento, produto de rigorosa reflexão e pesquisa, como instrumento importante a subsidiar a intervenção social em qualquer campo ou dimensão.

\section{REFERÊNCIAS}

ADRIÃO, T. Indicações e reflexões sobre as relações entre esferas públicas e privadas para a oferta educacional no Brasil. Políticas Educativas, v. 3, p. 1-1, 2009.

ADRIÃO, T. Dimensões da privatização da educação básica no Brasil a partir de 1990: Um diálogo com a produção acadêmica. Tese (Livre Docência). Faculdade de Educação, Unicamp, 2015.

ADRIÃO, T.; GARCIA, T.; BORGHI, R.; Bertagna, R.; MOEHLECKE, S. Mapeamento das Estratégias de privatização da Educação Básica no Brasil (2005-2015). (Relatório de pesquisa-CNPq), 2018.

LIMA, L. Apresentação da seção temática - Privatização da educação no contexto da(s) "Terceira(s) Via(s)": uma caracterização em análise. Currículo sem Fronteiras, v. 13, n. 2, p. 177-181, maio/ago. 2013. Disponível em:

http://www.curriculosemfronteiras.org/vol13iss2articles/apresentacao.pdf. Acesso em: 28 de maio 2018.

GARCIA, T.; ADRIÃO, T. (Org.) Currículo, gestão e oferta da educação básica brasileira: incidências de atores privados nos sistemas estaduais (2005-2015). Curitiba: CRV, 2018 .

GARCIA, T.; ADRIAO, T. M. F.; BORGHI, R.; A Nova Gestão Pública e o contexto brasileiro. In: Martins, A.M. (Org.). Instituições educacionais: políticas, gestão e práticas profissionais. 1. ed. Santos: Editora Leopoldianum-Universidade Católica de Santos, 2009, v. 1, p. 9-23, 2009. 


\section{Como referenciar:}

GARCIA, Teise. Dossiê Dimensões de privatização na educação básica: diferentes contextos em análise. Revista on line de Política e Gestão Educacional, Araraquara, v. 22, n. esp. 3, p. 1236-1240, dez., 2018 ISSN: 1519-9029. DOI: 10.22633/rpge.v22iesp3.12015

Submetido em: 10/10/2018

Aprovado em: 16/11/2018 